Canadian



Canadian Geotechnical Journal Revue canadienne de géotechnique

\title{
Effect of polyaniline coated galvanized steel electrodes on electrokinetic sedimentation of dredged mud slurries
}

\begin{tabular}{|r|l|}
\hline Journal: & Canadian Geotechnical Journal \\
\hline Manuscript ID & cgj-2016-0127.R1 \\
\hline Danuscript Type: & Article \\
\hline Complete List of Authors: & $\begin{array}{l}\text { Malekzadeh, Mona; JAMES COOK UNIVERSITY, School of Engineering \& } \\
\text { Physical Sciences } \\
\text { Sivakugan, Nagaratnam; James Cook University, } \\
\text { Kazum, Oluwole; James Cook University Faculty of Science and } \\
\text { Engineering, Chemical engineering } \\
\text { Mathan, Bobby; James Cook University, College of Science, Technology \& } \\
\text { Engineering }\end{array}$ \\
\hline Keyword: & $\begin{array}{l}\text { Polyaniline coating, soil improvement, galvanized steel, anode, dredged } \\
\text { marine sediments }\end{array}$ \\
\hline &
\end{tabular}


Title: Effect of polyaniline coated galvanized steel electrodes on electrokinetic sedimentation of dredged mud slurries

\section{Malekzadeh M.}

PhD Candidate, MSc, BSc in Civil Engineering, School of Engineering \& Physical Sciences, James Cook University, Townsville, QLD. 4811, Australia; PH +61 7478 15685; email: mona.malekzadeh@my.jcu.edu.au

\section{Sivakugan $\mathbf{N}$.}

Associate Professor, PhD, RPEQ, FASCE, Discipline of Civil Engineering School of Engineering \& Physical Sciences, James Cook University, Townsville, QLD. 4811, Australia; PH +61 7478 14431; email: siva.sivakugan@jej.edu.au

\section{Kazum O.}

Discipline of Chemical Engineering, School of Engineering Physical Sciences, James Cook University, Townsville, Queensland 4811, Australia PH +61 74781 5080; email: oluwole.kazum@my.jcu.edu.au

\section{Mathan B.}

Discipline of Chemical Engineering, School of Engineering Physical Sciences, James Cook University, Townsville, Queensland 4811, Australia PH +61 74781 5080; email: bobby.mathan@jcu.edu.au 


\section{Abstract:}

An experimental study on electrokinetic improvement of dredged marine sediments to accelerate their sedimentation for land reclamation purposes is presented. Electrokinetic stabilization is currently used to improve soils, however, its use on soils with marine sediments with low permeability is still questionable due to the deterioration of anodes caused by electrolysis reaction. A number of traditional methods are employed in literature to reduce the corrosion degradation of metals such as painting, galvanizing and conversion coating. Conducting polymers such as polyaniline is of engineering interest due to its properties such as ease of preparation and its high environmental stability in protecting metals from corrosion. For this purpose, the anodes used in electrokinetic testing cell herein were coated with polyaniline to investigate the effect on electrokinetic stabilization of the dredged mud. Two series of experiments were performed using a polyaniline coated galvanized steel anode, and two series of experiments with non-coated galvanized steel anodes as a control were also carried out. Depending on the applied voltage, the settlement and electroosmotic permeability of the dredged mud varied during the process. Polyaniline coating increased the power consumption during the electrokinetic stabilization compared to the case where the same electric potential is applied using the uncoated electrodes. However, when $5 \mathrm{~V}$ electric potential is applied to the soil through the polyaniline coated anode, its settlement and electroosmotic permeability are equivalent to what was observed with $30 \mathrm{~V}$ electric potential applied through the non-coated anode, with 3 times less energy consumption.

Keywords: Polyaniline coating; soil improvement; galvanized steel; anode; dredged marine sediments; 


\section{Introduction}

3 Dredged marine sediments are characterized by their low permeability which results in long

4 durations of settlement. To accelerate the sedimentation and consolidation of the dredged

5 sediments, electrokinetic stabilization seems to be an effective method. Electrokinetic

6 stabilization was first trialled by Casagrande (1949) to improve the properties of soils. However,

7 a specific design standard has not yet been developed, due to the complex electrochemical

8 reactions that happen in the soil during electrokinetic stabilization and parameters that affect the

9 process such as $\mathrm{pH}$, type of minerals in the soil, salt content and soil resistivity. The effect of

10 these parameters and the chemical reactions in the soil cause permanent changes in the soil and

11 result in an increase in strength properties of soils (e.g. Micic et al. 2001; Rittirong et al. 2008).

12 Electrical field parameters such as the type of electrodes have significant effect on the efficiency

13 of the electrokinetic stabilization. The type of the electrode affects the electrokinetic stabilization

14 based on their reaction that takes place with the soil minerals and loss of voltage within the soil

15 (Mohamedelhassan and Shang 2001). Metal electrodes are susceptible to corrosion due to the

16 acidity of the environment near the anode caused by the electrolysis reaction at anode. A number

17 of traditional methods are employed to reduce the corrosion degradation of metals such as

18 painting, galvanizing and conversion coating. Recent years have seen a rise of interest in using

19 conducting polymers for the corrosion protection of metals. This is due to their attractive

20 properties such as corrosion inhibition, ease of preparation and high environmental stability.

21 Galvanized steel is one of the most common, easily accessible and inexpensive metals for use in

22 electrokinetic stabilization. However, it is one of the metals that is more easily corroded.

23 Therefore, in this study a conductive polymer referred to as Polyaniline is Galvano-statically 
24 coated on galvanized steel and the effect of the coating on electrokinetic sedimentation 25 properties of the dredged mud is investigated.

\section{Experimental study:}

\section{Laboratory Set-up}

28 An electrokinetic testing cell shown in Figure 1 is used to investigate the settling behaviour of the dredged sediments during electrokinetic stabilization. The following aspects were considered in selecting this set-up.

a) Settlement columns: settlement columns were chosen to monitor the changes of interface height with time, which shows the sedimentation of the dredged mud.

b) Placement of anode at the bottom: The flow of water is mostly from the anode to the

44 Four Perspex settlement columns with an inner diameter of $90 \mathrm{~mm}$, height of $500 \mathrm{~mm}$ and $3 \mathrm{~mm}$

45 wall thickness were used. Two electrodes made of galvanized steel with the size of $88 \mathrm{~mm}$ are

46 placed horizontally at the bottom and the top of the settlement column. The top electrode, the 
47 cathode, is removable for ease of sample preparation. The top electrode is placed in contact with 48 the sediment and will therefore move as the interface height changes.

\section{Figure 1}

50

\section{Material properties}

\section{Soil:}

53 Remoulded dredged mud with specific gravity of 2.61, which was measured using AS

54 1289.3.5.1, is used herein. The samples of dredged mud are taken from the land reclamation area 55 at the port of Brisbane, Australia. To simulate the consistency of the slurry as it is pumped into

56 the paddocks, the moisture content of the sediment was measured and brought up to $250 \%$ by

57 adding more distilled water. Distilled water added to keep the concentration of salt similar to the 58 initial condition where the samples of dredged mud is received from the port. To ensure the 59 homogeneity of the samples, a mixer was used to mix the water with the sediments properly and 60 the slurry was then left for 24 hours before pouring into the settlement column. The liquid limit 61 and plastic limit of the dredged mud were obtained according to AS 1289.3.9.1 and AS 62 1289.3.2.1, respectively. The plasticity index of the dredged mud was $52 \%$ whilst the liquid limit 63 was 92\%. Therefore based on United States soil Classification System, the sediment is classified 64 as clay of high plasticity $(\mathrm{CH})$. The linear shrinkage of the soil was measured according to AS $65 \quad 1289.3 .4 .1$ and found to be $33 \%$.

\section{Materials:}

67 Galvanized steel: Galvanized steel was used in this study, due to its low cost and availability. 68 Galvanized steel is typically steel that is coated with a layer of zinc oxide to reduce its rate of 69 corrosion. 
Galvanized steel sheet with thickness of $2 \mathrm{~mm}$ : Galvanized steel sheet with thickness of $2 \mathrm{~mm}$

71 was cut into circular plates and perforated for better drainage from the top to be used as the

72 cathode.

73 Galvanized steel sheet with thickness of $5 \mathrm{~mm}$ : To reduce the time at which the anode corrodes,

74 which interrupts the current flow through the soil, a thicker sheet of galvanized steel was used as

75 an anode.

76 Polyaniline coating: Polyaniline coating is a widely used conductive polymer that is used to

77 increase the aqueous corrosion resistance of metals (Santos et al. 1998). During electrokinetic

78 sedimentation of soils, the $\mathrm{pH}$ near the anode reduces due to the electrolysis and this results in

79 corrosion of the anode and disruption of the electrokinetic process. Polyaniline is obtained by

80 electrochemical oxidation and polymerization of aniline (Skotheim and Reynolds 2007) which

81 has unique properties such as being a low cost monomer, high electrochemical activity, stability,

82 and optical activity (Gvozdenovic et al. 2012). As polyaniline is very effective in reducing the

83 corrosion especially in an acidic environment (MacDiarmid and Ahmad 1997), it was chosen as

84 the coating material.

85 Methodology:

86 Anode modification:

87 Polyaniline coated anode: The anode was made, using a 5mm thick galvanized steel sheet with

88 diameter of $900 \mathrm{~mm}$ that is coated with Polyaniline to reduce its corrosion rate. Polyaniline

89 coating is usually done by methods such as direct deposition from solvents, electrochemical

90 synthesis, and coating with various commercial coatings such as epoxy, polyester, and acrylic

91 (Gvozdenovic et al. 2012). In this study, the coatings were performed by electrochemical

92 synthesis. Galvanized steel is steel that is coated with a layer of zinc oxide, forming the bond 
93 between polyaniline and the layer of zinc oxide was challenging and the first trial coating was 94 not successful. For this reason, samples were ground with SiC papers up to 1200 grit, followed 95 by ultrasonic cleaning in acetone and ethanol to eliminate any dirt prior to coating. The synthesis 96 of polyaniline coating on the steel was done by the Galvano-static technique using a Potentiostat 97 (Model: VersaSTAT3 PAR) with a three-electrode cell, Steel is used as a working electrode, 98 silver/silver-chloride is used as a reference electrode, and graphite as a counter electrode, and the coating bath was an electrolyte containing $0.3 \mathrm{M}$ aniline and $0.1 \mathrm{M}$ aqueous sodium salicylate solution. Each coating was done under a high current density of $20 \mathrm{~mA} . \mathrm{cm}^{-2}$, applied for $10 \mathrm{~min}$.

101 For more detail information on how the polyaniline coating is done refer to Kazum and Mathan 102 (2013).

\section{General procedure:}

104 When the anodes had been coated, they were attached to the plain Perspex sheet that is used as 105 the impervious base at the bottom of the settlement column. To allow for the wire that is 106 connected to the anode, a hole with diameter of $6 \mathrm{~mm}$ was drilled through at the centre of the 107 base. The hole was later sealed with silicon once the wire is fed through. The Perspex base was 108 then screwed to the rim of the settlement column after placing a filter paper on top of the anode.

109 The soil slurry was then poured into the column at once using a funnel assuming there would be 110 no lag time. The cathode is then placed on top of the soil specimen after placing a filter paper. 111 The wires are then connected to the poles, positive pole for anode, negative pole for cathode, and 112 the DC supply is turned on, applying a constant voltage of $30 \mathrm{~V}$ and the changes of electric 113 current and interface height with time is monitored.

\section{Results and discussion:}

\section{Variation of current density with time}


116 The constant electric potential of $30 \mathrm{~V}$ or $5 \mathrm{~V}$ were applied to the dredged mud. When the

117 electric potential was applied, the electric current was monitored for all cases until the tests were

118 completed. Because electric current varied similarly in $30 \mathrm{~V}$ coated and $30 \mathrm{~V}$ non-coated tests, the

119 fitting curves coincide at $\mathrm{t}_{\mathrm{opt}}$ (Figure 2). Referring to the figure, when $5 \mathrm{~V}$ electric potential was

120 applied to the soil through the coated anode, the pattern of changes in electric current with time

121 was similar to when $30 \mathrm{~V}$ was applied through the coated anodes. This shows that the polyaniline

122 coating increased the efficiency of the method by reducing the soil resistivity. However, this only

123 happened when low voltage of $5 \mathrm{~V}$ was applied. In case where electric potential of $30 \mathrm{~V}$ was

124 applied through the coated anode, the soil resistivity was higher than the case of non-coated

125 anode. This shows that the polyaniline coating was disintegrated at voltage of $30 \mathrm{~V}$, resulting in

126 higher resistivity and power consumption in comparison with non-coated anode.

\section{Figure 2}

129

As electric current and resistivity of the soil change with time and as soil particles settle, the

131 density of the soil changes, and as a result the settling velocity varies. The variation of settling

132 velocity with changes of electric current is given in Figure 3. The settling velocity of the soil is

133 shown to be at its maximum when the electric current is the maximum. The polynomial

134 regressions to the measured settling velocities with respect to changes of electric current with 135 application of $5 \mathrm{~V}$ and $30 \mathrm{~V}$ electric potential through coated and non-coated electrodes, are 136 defined as:

137 When $30 \mathrm{~V}$ electric potential is applied through coated anode:

$V_{s}=-32.45 I^{2}+19.28 I+0.53$ 
139 When $5 \mathrm{~V}$ electric potential is applied through coated anode

140

$V_{s}=-31.55 I^{2}+18.56 I+0.564$

141 When $30 \mathrm{~V}$ electric potential is applied through non-coated anode

$142 V_{s}=-27.14 I^{2}+5.22 I+0.29$

143 When $30 \mathrm{~V}$ electric potential is applied through non-coated anode

$144 V_{s}=-4.09 I^{2}+5.79 I+1.07$

145 where $V_{S}$ is the settling velocity in $\mathrm{mm} / \mathrm{hr}$ and $I$ is the electric current in Amps. These regression 146 equations are valid for electric current ranging from 0 to $1 \mathrm{amp}$ showing that the electric current

147 of the soil does not exceed $1 \mathrm{amp}$ when $30 \mathrm{~V}$ electric potential is applied. The settling velocity 148 based on electric current gives an information about soil resistivity. Since soil resistivity is a 149 function of chemical changes in the soil, therefore it is necessary to investigate the relationship 150 between settling velocity based on application of electric current. The maximum settling velocity 151 is obtained at electric current of 0.3 amps in case of coated anode, and 0.6 amps in case of $30 \mathrm{~V}$ 152 non-coated electrode, and less than 0.1 amps for when $5 \mathrm{~V}$ electric potential is applied.

\section{Figure 3}

156 The maximum electric current at optimum time and maximum electric current at maximum 157 settling velocity that is obtained for each case is given in Table 1 . When $30 \mathrm{~V}$ is applied through 158 the non-coated anode, the maximum electric current is reached as soon as 8 hours. Whereas, if 159 the anode is not coated, the maximum electric current with applying the same voltage is reached 160 in 18 hours. When electric potential of $5 \mathrm{~V}$ is applied through the coated anode, same amount of 161 time is required to reach the maximum electric current. This shows that polyaniline coating 
162 improved the electrokinetic stabilization of the dredged mud if $5 \mathrm{~V}$ electric potential is applied 163 and resulted in lower power consumption and higher electrokinetic efficiency.

164 Settling velocity is based on the hydraulic and electroosmotic permeability of the soil. Therefore, 165 the relationship between electric current and settling velocity given in this section shows that the 166 highest hydraulic and electroosmotic permeability was achieved at electric current of 0.3 amps 167 when anodes are coated. Whereas, the ultimate current for non-coated anodes is twice the coated 168 anode for application of $30 \mathrm{~V}$ electric potential and less than half for application of $5 \mathrm{~V}$ electric 169 potential. Therefore, application of constant $I_{v(\max )}$ is suggested electric current to obtain the 170 maximum possible settlement. Use of $I_{v(\max )}$ as the design electric current result in lowest power 171 consumption and maximum settlement.

\section{Table 1}

173

\section{Electrokinetic sedimentation}

175 The changes of interface height with time is shown in Figure 4. It is shown that if $5 \mathrm{~V}$ electric

176 potential is applied through coated anode the sedimentation behaviour of the soil is similar to 177 when $30 \mathrm{~V}$ constant electric potential is applied. Application of $30 \mathrm{~V}$ electric potential through 178 coated anode did not significantly change the final settlement of the soil, and only $11 \%$ increase 179 in final settlement of the dredged mud is observed. This is due to the disintegration of the 180 polyaniline coating at higher voltage of $30 \mathrm{~V}$, and is attributed to the unknown chemical 181 reactions resulting from the interaction between polyaniline coating and dredged mud particles, 182 or changes in resistivity of the anode by applying the polyaniline coating. However, when $5 \mathrm{~V}$ 183 electric potential is applied through polyaniline coated anode, the final settlement of the dredged 184 mud increased to $73 \%$ of the final settlement of the dredged mud in case of non-coated anode. 
185 The logarithmic regression that is the best fit of the experimental data shows the settlement of the 186 dredged mud at any time during electrokinetic stabilization given as:

187 When $5 \mathrm{~V}$ electric potential is applied through coated anode:

$188 S=-47.38 \ln (t)+472.84$

189 When $5 \mathrm{~V}$ electric potential is applied through non-coated anode

$190 S=-31.521 \ln (t)+475.03$

191 When $30 \mathrm{~V}$ electric potential is applied through coated anode

$192 S=-45.1 \ln (t)-463.69$

193 When $30 \mathrm{~V}$ electric potential is applied through non-coated anode

$194 S=-38.37 \ln (t)-438.61$

195 where $\mathrm{S}$ is the settlement of the soil with time and $\mathrm{t}$ is the time interval in hours. These 196 correlations are true for the dredged mud with the presented initial state and under the given 197 laboratory condition.

\section{Figure 4}

\section{Electrokinetic sedimentation coefficient}

201 The electrokinetic sedimentation coefficient is the slope of the porosity and settling velocity of 202 the slurries. The sedimentation coefficient is related to the process of hindered settling prior to 203 consolidation and it is similar to the coefficient of consolidation during the process of 204 consolidation. When slurry settles, concentration of solids increases with time. As a result, the 205 porosity and the settling velocity of the particles reduces (Mohamedelhassan and Shang 2001). 
206 According to Zaki and Richardson (1954) the velocity of suspension $V(\mathrm{~m} / \mathrm{s})$ depends on porosity

$207(n)$ and coefficient of sedimentation $(r)$ :

$208 \quad r=\log _{n}\left(\frac{U}{V}\right)$

209 where $U$ is the particle settling velocity $(\mathrm{m} / \mathrm{s})$ :

$210 \quad U=\frac{g\left(\rho_{s}-\rho_{f}\right) d^{2}}{18 \mu}$

211 where $\mathrm{g}$ is gravitational acceleration $\left(\mathrm{m} / \mathrm{s}^{2}\right), \rho_{s}$ and $\rho_{f}$ are density of solid and fluid respectively

$212\left(\mathrm{~kg} / \mathrm{m}^{3}\right), \mathrm{d}$ is diameter of particles $(\mathrm{m})$, and $\mu$ is the viscosity of fluid $\left(\mathrm{N} . \mathrm{s} / \mathrm{m}^{2}\right)$. The coefficient of 213 sedimentation can be determined from the plot of settling velocity and porosity. In this study the 214 settling velocity and the porosity is determined using following equations:

$215 n=\left(\frac{e}{1+e}\right) \times 100$

216 where e is the void ratio, and $\mathrm{n}$ is the porosity in percent. The settling velocity $(\mathrm{mm} / \mathrm{hr})$ of the 217 slurry based on changes of interface height is determined from:

$218 V_{s}=\frac{\Delta H}{\Delta t}$

219 where $\Delta H$ is the changes of interface height in $(\mathrm{mm})$ within time interval of $\Delta t(\mathrm{hr})$.

220 The variation of coefficient of sedimentation versus porosity is shown in figure 5 . The settling 221 velocity increases as porosity increases up to $81 \%$ after which it reduces. The experiment starts 222 initially with porosity of $86 \%$ which gradually reduces as sediment settles. In case of $5 \mathrm{~V}$ non223 coated anode, the settling velocity did not change significantly. However, in case of $30 \mathrm{~V}$ non224 coated, the settling velocity increases to a peak of $84 \%$ after which, it reduces progressively to a 225 final porosity of $77 \%$. Both cases of coated anodes follow a similar pattern. In both cases, the 
226 settling velocity starts at a relatively slow rate and increases progressively up to a maximum

227 velocity, at porosity of $82 \%$, then it reduces gradually reaching a final porosity of $74 \%$.

228 The sedimentation coefficient increases when properties such as clay content of the soil increases

229 (Shang 1997). The polyaniline contributes to changes in the properties of the dredged mud

230 through unknown chemical reactions which result in better electrokinetic settlement and

231 efficiency. The coefficient of electrokinetic sedimentation is calculated from the left hand side of

232 the slope of the settling velocity versus porosity. The left side of the graph is related to the initial

233 peak of the electric current, and first half of the settlement before consolidation, and the right

234 hand side of the graph is considered as consolidation stage. Therefore, the coefficient of

235 sedimentation is determined using the left hand side of the settling velocity versus porosity plot.

236 The coefficient of sedimentation is $0.46 \mathrm{~mm} / \mathrm{hr}, 0.98 \mathrm{~mm} / \mathrm{hr}, 0.11 \mathrm{~mm} / \mathrm{hr}$, and $0.14 \mathrm{~mm} / \mathrm{hr}$ for 5

$237 \mathrm{~V}$ non-coated anode, $30 \mathrm{~V}$ non-coated anode, $5 \mathrm{~V}$ coated anode, and $30 \mathrm{~V}$ coated anode,

238 respectively.

239 This shows that for coated anodes, the increase in voltage does not significantly change the 240 settling velocity of the dredged mud. The electrokinetic sedimentation depends on the intrinsic 241 properties of the clay and current density. The results reported in this study are in agreement with 242 the findings of Shang (1997).

Figure 5

244

245

\section{Electroosmotic permeability parameters:}

246 The soil settling velocity is based on electroosmotic permeability of the soil, and the 247 effectiveness of the electrokinetic dewatering depends on electroosmotic permeability $k_{e}$. 248 Electroosmotic permeability is measured using the equation given by Mitchell (1993): 
$249 q_{e o}=k_{e} A \frac{j}{\sigma}$

250 where $q_{e o}$ is the flow rate of water $\left(\mathrm{m}^{3} / \mathrm{s}\right), k_{e}$ is electroosmotic permeability $\mathrm{m}^{2} /(\mathrm{s} . \mathrm{V}), A$ is 251 cross-sectional area between electrodes, $j$ is current density in $\mathrm{A} / \mathrm{m}^{2}$, and $\sigma$ is the electrical 252 conductivity of the dredged mud slurry $(\mathrm{S} / \mathrm{m})$.

253 As dredged mud slurry settles, the electroosmotic flow reduces with time. The flow rate of water

$254\left(q_{e o}\right)$ that is induced by application of electric current is measured using the volume of drained 255 water within the time interval when interface height changes. Figure 6 shows the changes of 256 electroosmotic permeability with void ratio. The electroosmotic permeability of the dredged mud 257 reduced with reduction of void ratio. The responses of dredged mud to $30 \mathrm{~V}$ electric potential 258 that was applied through coated and non-coated anodes were similar. Therefore, their fitting 259 curves are nearly coincident. According to Malekzadeh and Sivakugan (2016), the 260 electroosmotic permeability parameter which is assumed to be dependent on changes of interface 261 height and index properties of the soil is given as:

$262 k_{e}=C^{*} e^{D^{*}}$

263 where $C^{*}$ and $D^{*}$ are electroosmotic permeability parameters and $e$ is void ratio. According to 264 this equation the electroosmotic permeability parameters derived from the performed 265 experiments are as follows:

2665 volt non-coated anode: $C^{*}=2 \times 10^{-6}, D^{*}=2.45$

26730 volt non-coated anode: $C^{*}=7 \times 10^{-6}, D^{*}=2.74$

2685 volt coated anode: $C^{*}=3 \times 10^{-5}, D^{*}=1.77$

26930 volt coated anode: $C^{*}=7 \times 10^{-6}, D^{*}=2.74$ 


\section{Figure 6}

\section{Power consumption:}

276 The power consumption in this study is based on two variables. One is the electric current which

277 changes with changes of soil resistivity and time and the other variable is the distance between

278 electrodes, since the cathode moves downward with as interface height changes. Therefore, the

279 following equation is used to determine the consumption of energy.

$280 \quad P=\frac{d I}{d l} \times \frac{V}{A} \times \Delta t$

281 where $P$ is the power consumption $\left(\mathrm{W} . \mathrm{s} / \mathrm{m}^{3}\right)$ to settle the volume of sediments noted as $d l$

282 (changes in distance between electrodes), with a constant applied voltage of $V$ (Volts), which 283 generates an electric current difference of $d I$ (Amps) within a time interval of $\Delta t$ in hours 284 through cross sectional area $\mathrm{A}\left(\mathrm{m}^{2}\right)$.

285 The energy consumption for treating 1 cubic meter of dredged mud when constant electric 286 potential of $5 \mathrm{~V}$ and $30 \mathrm{~V}$ electric potential is applied to the soil through coated and non-coated

287 anodes is shown in Table 2. The consumption of energy when a non-coated anode is used with a 288 voltage of $5 \mathrm{~V}$ is $1.97 \mathrm{kWh} / \mathrm{m}^{3}$ which is very low in comparison with the other cases, however, 289 the percent settlement is relatively lower than other cases too. When $5 \mathrm{~V}$ electric potential is 290 applied to the dredged mud through the coated anode the power consumption increases 1.8 times 291 the case of non-coated anode. However, the coating increases the settlement up to 9.8 times. The 292 power consumption increase when the anode is coated with polyaniline. This is attributed to the 
293 lower conductivity of polyaniline coating in comparison with the non-coated anode. The choice

294 of whether to apply the polyaniline coating needs to be based on the budget and timeline of the 295 project. The coated anode with application of $5 \mathrm{~V}$ constant electric potential is suggested as an 296 effective anode for maximum electrokinetic efficiency.

\section{Table 2}

\section{Conclusion:}

300 This study investigated the effect of polyaniline coating on the electrokinetic dewatering and 301 sedimentation of dredged sediments through comparisons of coefficient of sedimentation, 302 electroosmotic permeability, and changes in electric current which is an indication of soil 303 resistivity, and power consumption. The dredged marine sediments used here were taken from the reclamation site in the port of Brisbane. The following conclusions can be drawn:

- The application of $5 \mathrm{~V}$ electric potential to dredged sediments using a coated anode induces a similar settling behaviour to applying $30 \mathrm{~V}$ of electric potential through either coated or non-coated anodes.

- For the cases of; $30 \mathrm{~V}$ applied through a coated and non-coated anode, and 5V applied through a coated anode, the variation of electric current with time, electroosmotic permeability, settlement, and sedimentation coefficient were all similar. In contrast, when $5 \mathrm{~V}$ electric potential is applied through the non-coated anode, the power consumption, settlement, electroosmotic permeability and sedimentation coefficient are noticeably lower when compared with all three of the other cases.

- It is shown that applying a layer of coating on the anode increases the power consumption considerably, due to its lower conductivity in comparison with non-coated 
316

317

318

319

320

321

322 Based on this study, the application of $5 \mathrm{~V}$ electric potential with a coated anode would appear to

323 offer noticeable advantages, however the decision to use this method should be made with

324 consideration of the specific project features, including available budget and timeline. 


\section{References:}

Casagrande, I. 1949. Electro-Osmosis in Soils. Géotechnique, 1(3), pp.159-177.

Gvozdenović, M., Jugović, B., Stevanović, J., Grgur, B., Trišović, T. and Jugović, Z. 2011.

Electrochemical synthesis and corrosion behavior of polyaniline-benzoate coating on copper. Synthetic Metals, 161(13-14), pp.1313-1318.

Kazum, O. and Kannan, M. 2013. Galvano-static polymerisation of aniline on steel: Improving the coating performance in chloride-containing environment. Synthetic Metals, 180, pp.54-58.

MacDiarmid, A. G. and Ahmad, N. 1997. Prevention of corrosion with polyaniline: Google Patents.

Malekzadeh and Sivakugan N. 2016. Intermittent electro-consolidation of dredged sediments. Manuscript submitted for publication.

Malekzadeh M. and Sivakugan N. 2015. Effect of electrode placement on electrokinetic settlement. Manuscript submitted for publication.

Micic, S., Shang, J., Lo, K., Lee, Y. and Lee, S. 2001. Electrokinetic strengthening of a marine sediment using intermittent current. Canadian geotechnical journal, 38(2), pp.287-302.

Mitchell, J. 1993. Fundamentals of soil behaviour. New York: John Wiley \& Sons.

Mohamedelhassan, E. and Shang, J. 2001. Effects of electrode materials and current intermittence in electro-osmosis. Proceedings of the ICE - Ground Improvement, 5(1), pp.3-11. 
Rittirong, A., Shang, J., Mohamedelhassan, E., Ismail, M. and Randolph, M. 2008. Effects of Electrode Configuration on Electrokinetic Stabilization for Caisson Anchors in Calcareous Sand. J. Geotech. Geoenviron. Eng., 134(3), pp.352-365.

Santos, J., Mattoso, L. and Motheo, A. 1998. Investigation of corrosion protection of steel by polyaniline films. Electrochimica Acta, 43(3-4), pp.309-313.

Shang, J. 1997. Electrokinetic dewatering of clay slurries as engineered soil covers. Canadian Geotechnical Journal, 34(1), pp.78-86.

Skotheim, T. and Reynolds, J. 2007. Handbook of conducting polymers. Boca Raton, Fla.: CRC. 


\section{List of Figures:}

Figure 1. The electrokinetic cell used in this study

Figure 2. Variation of electric current with time during electrokinetic stabilization of dredged mud slurry

Figure 3. Variation of electric current with settling velocity during electrokinetic stabilization of dredged mud slurry

Figure 4. Changes of settlement versus time

Figure 5. Variation of settling velocity with porosity

Figure 6. Electroosmotic permeability versus void ratio

\section{List of tables:}

Table 1. Optimum time at which maximum electric current occurs

Table 2. Power consumption and percent settlement 




Figure 1 




Figure 2 


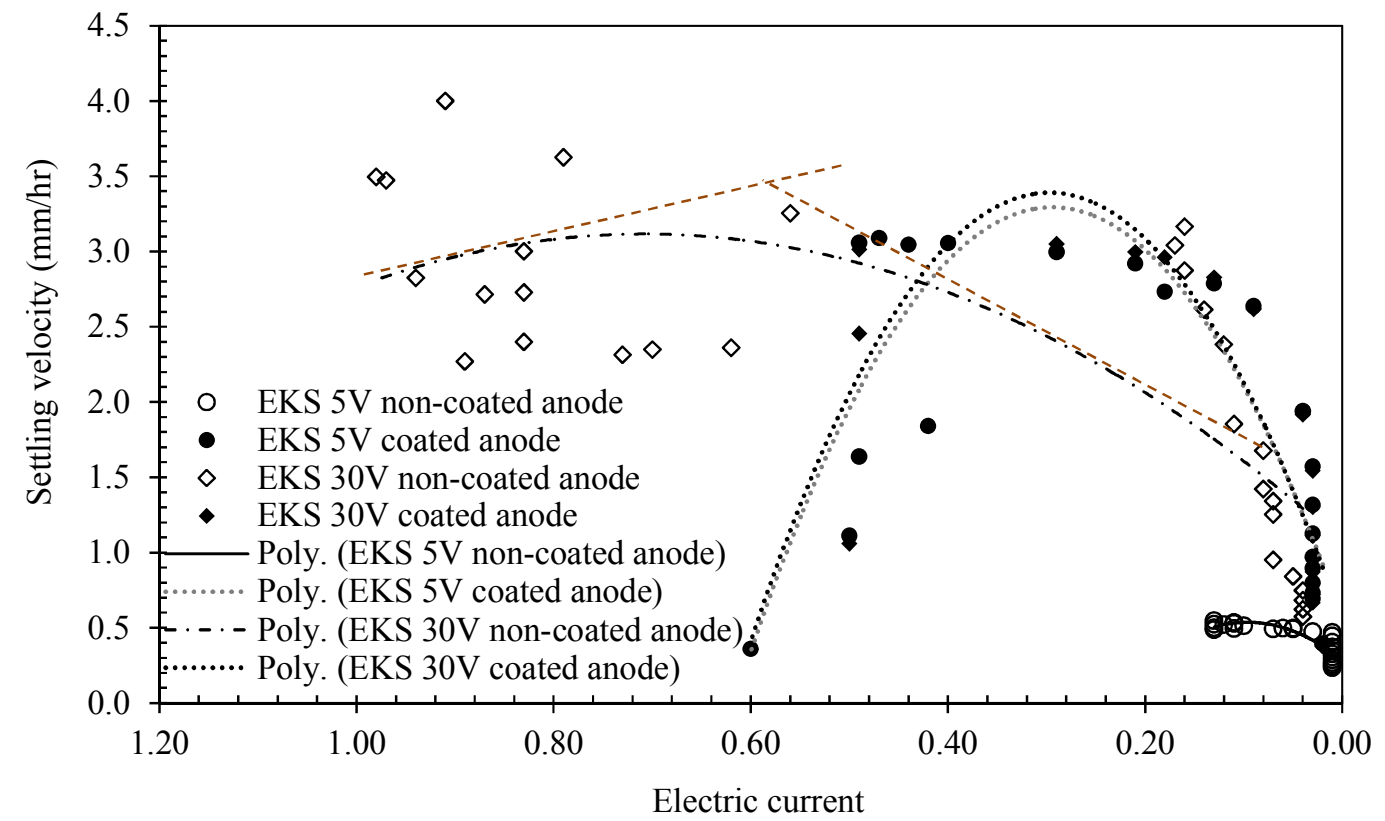

Figure 3 


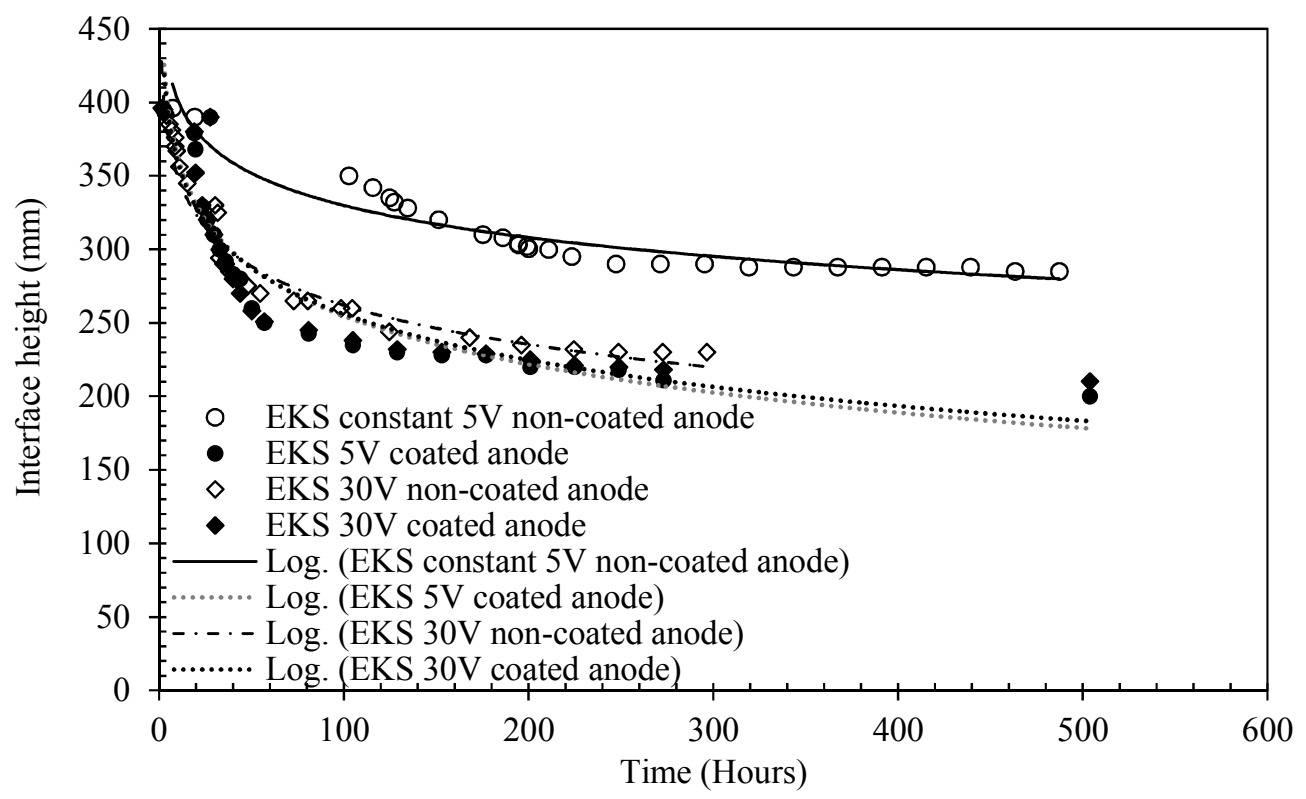

Figure 4 


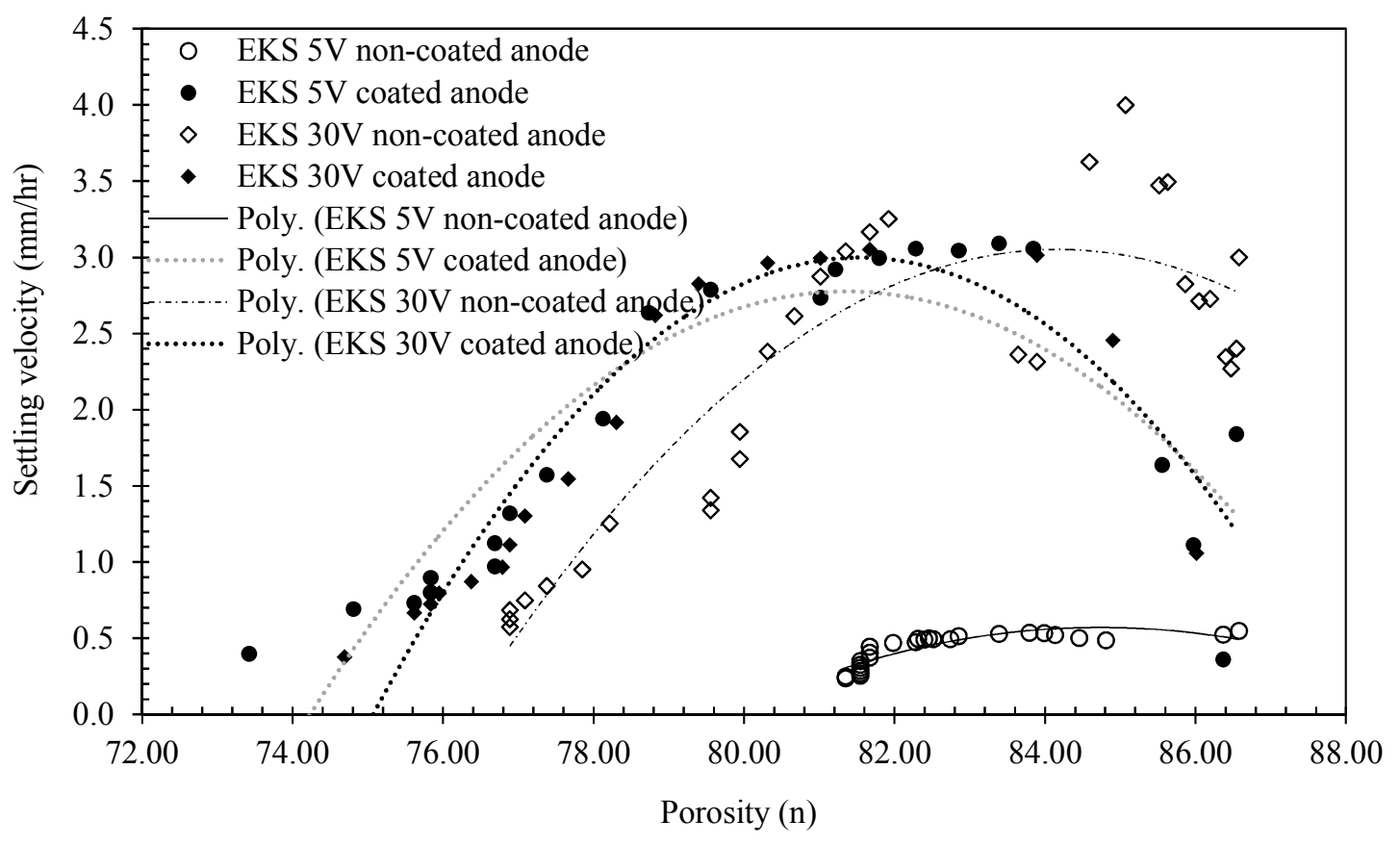

Figure 5 


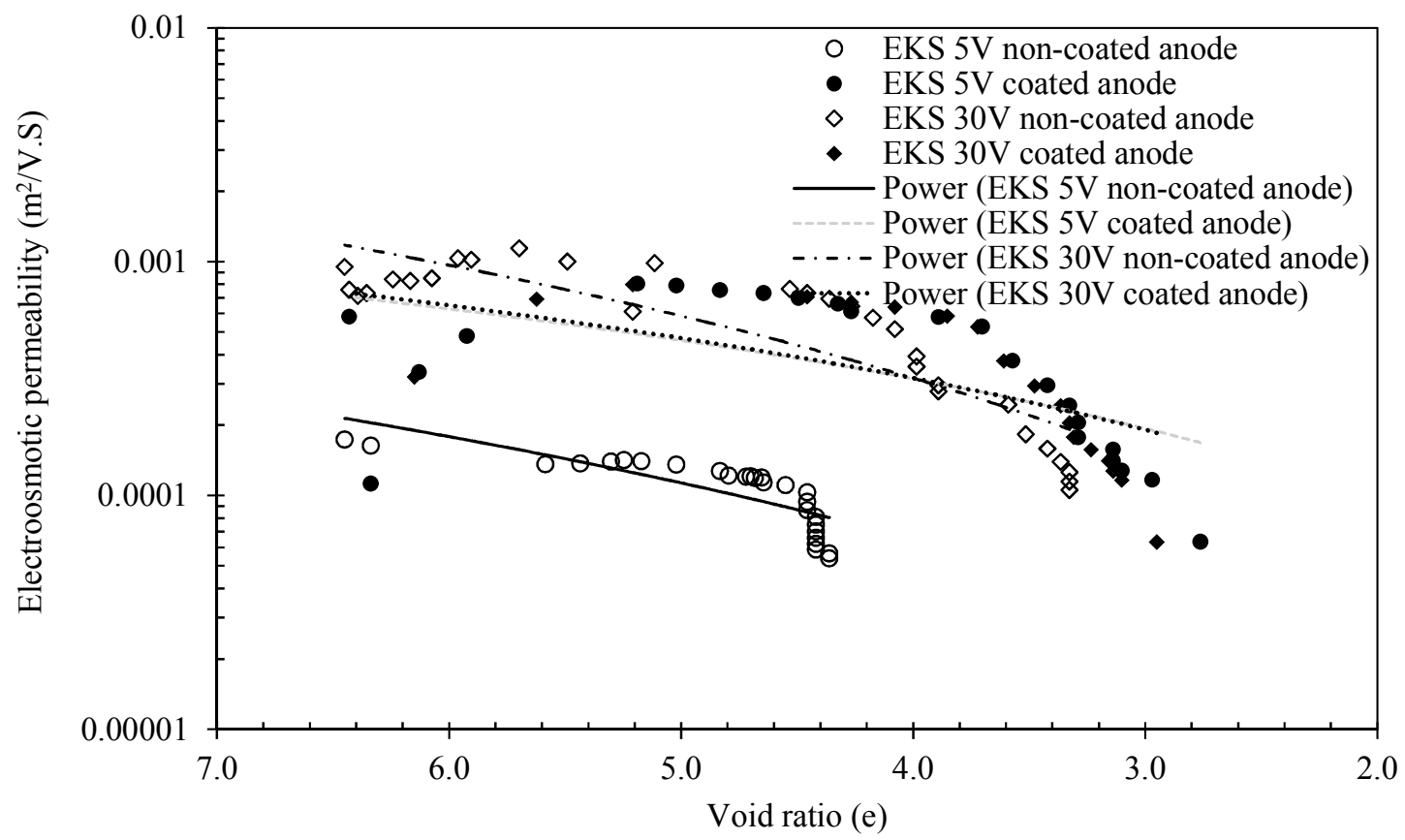

Figure 6 
Table 1. Optimum time at which maximum electric current occurs

\begin{tabular}{|c|c|c|c|c|}
\hline $\begin{array}{c}\text { Electrode condition } \\
\text { (anode) }\end{array}$ & $\begin{array}{c}\mathbf{V} \\
\text { (volts) }\end{array}$ & $\begin{array}{c}\text { Optimum time } \\
\mathbf{t}_{\text {opt }} \text { (Hours) }\end{array}$ & $\begin{array}{c}\mathbf{I}_{\text {max }} \\
\text { Maximum electric } \\
\text { current (Amps) }\end{array}$ & $\begin{array}{c}\mathbf{I V}_{\text {s (max) }} \\
\text { Electric current at } \\
\text { maximum } \mathbf{V}_{\mathbf{s}} \text { (Amps) }\end{array}$ \\
\hline Non-coated & 5.00 & 90 & 0.20 & $<0.1$ \\
Coated & 5.00 & 18 & 0.52 & 0.3 \\
Non-coated & 30.00 & 8 & 0.92 & 0.6 \\
Coated & 30.00 & 18 & 0.56 & 0.3 \\
\hline
\end{tabular}


Table 2. Power consumption and percent settlement

\begin{tabular}{|c|c|c|c|}
\hline $\begin{array}{c}\text { Electrode condition } \\
\text { (anode) }\end{array}$ & $\begin{array}{c}\text { Energy consumption } \\
\text { per } \mathbf{~ m}^{\mathbf{3}} \text { of dredged } \\
\text { mud }\left(\mathbf{k W h} / \mathbf{m}^{3}\right)\end{array}$ & $\begin{array}{c}\mathbf{V} \\
(\mathbf{v o l t s})\end{array}$ & $\begin{array}{c}\% \\
\text { settlement } \\
\left(\mathbf{\Delta H} / \mathbf{H}_{\mathbf{i}}\right) * \mathbf{1 0 0}\end{array}$ \\
\hline Non-coated & 1.97 & 5.00 & 28.75 \\
Coated & 19.34 & 5.00 & 50.00 \\
Non-coated & 71.88 & 30.00 & 42.50 \\
Coated & 112.73 & 30.00 & 47.50 \\
\hline
\end{tabular}




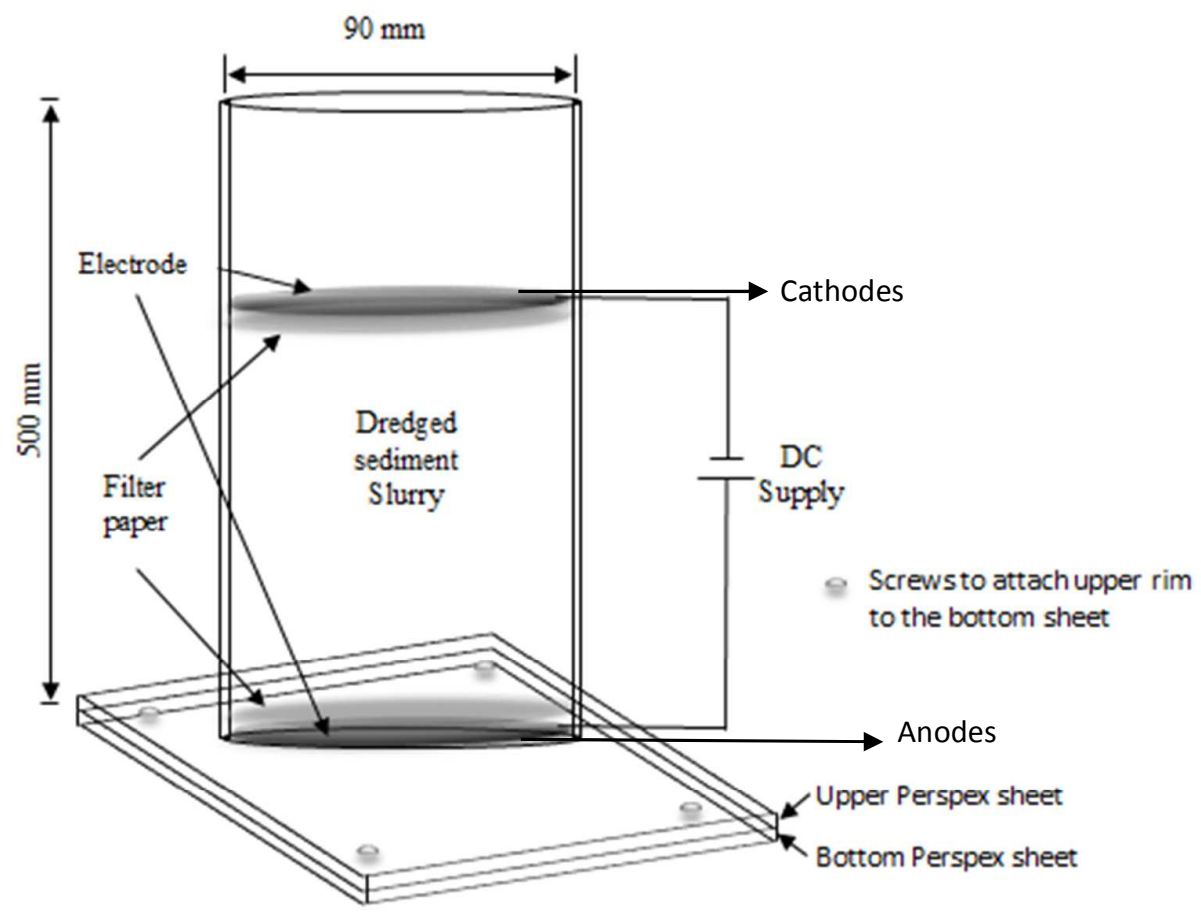

Figure 1 


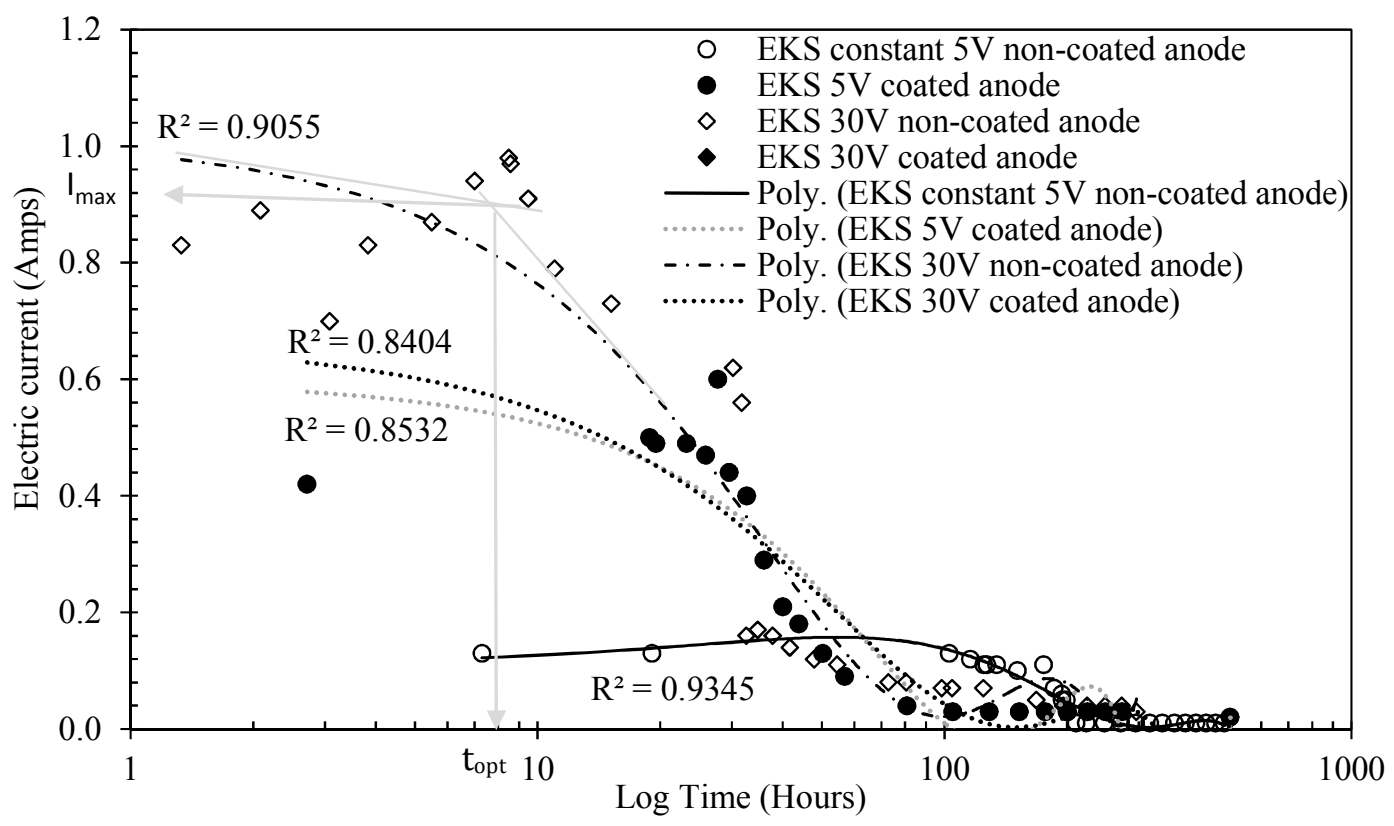

Figure 2 


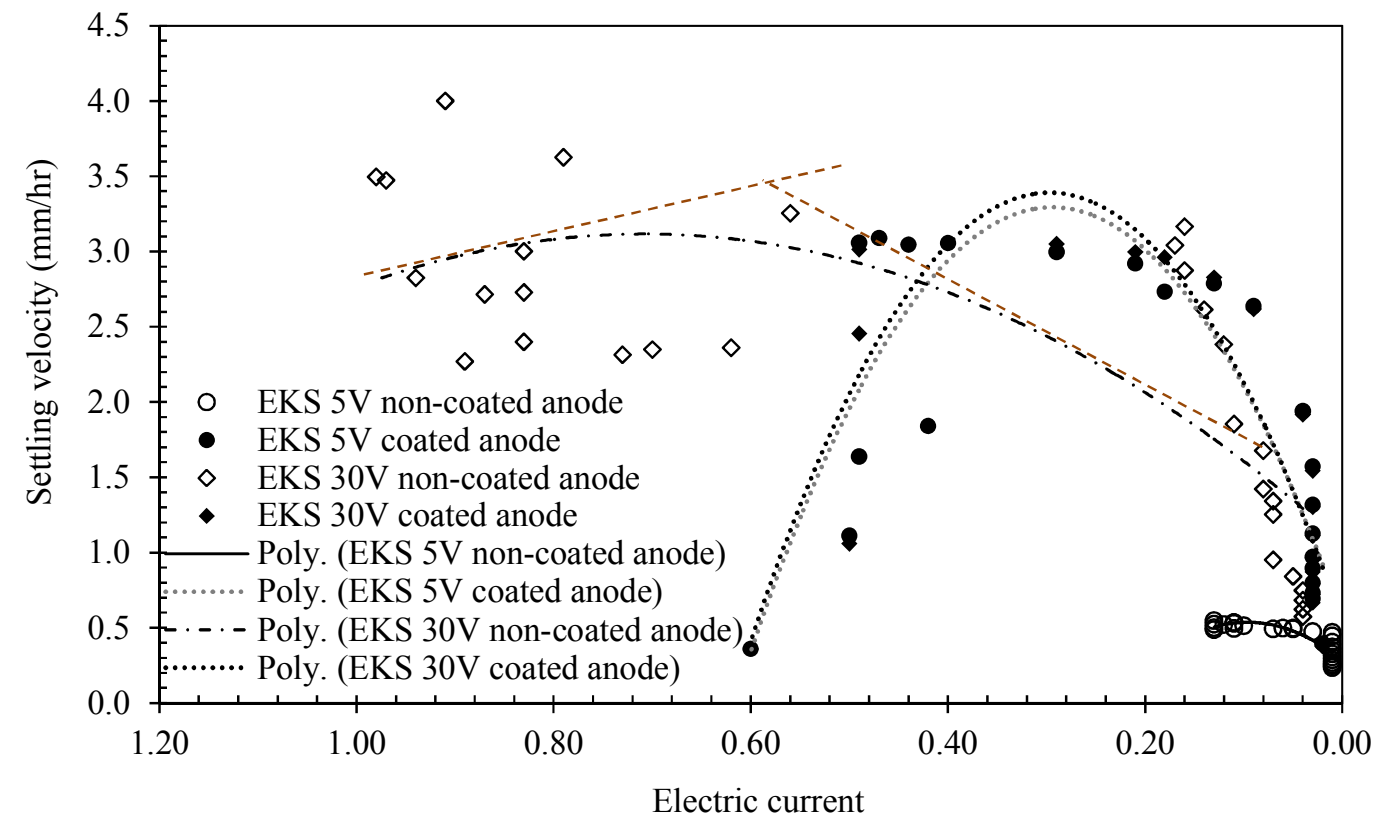

Figure 3 


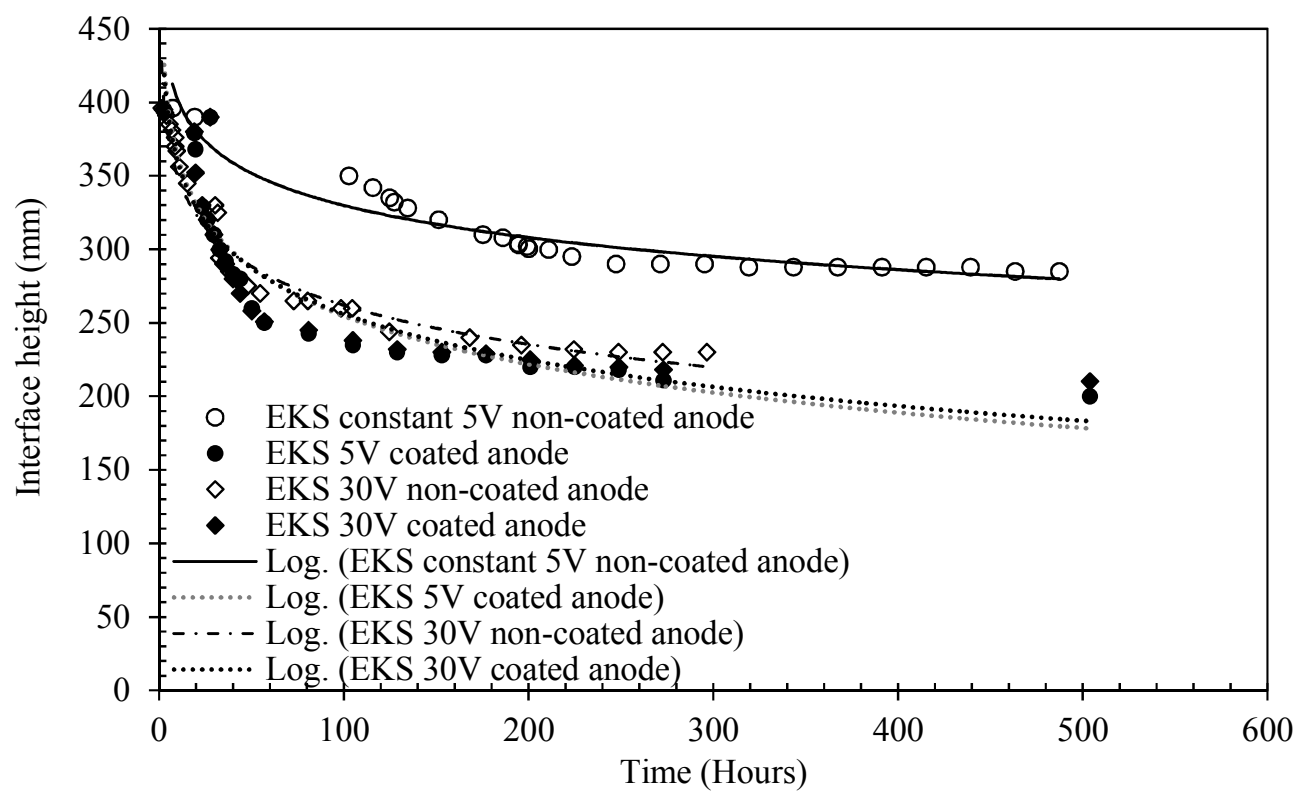

Figure 4 


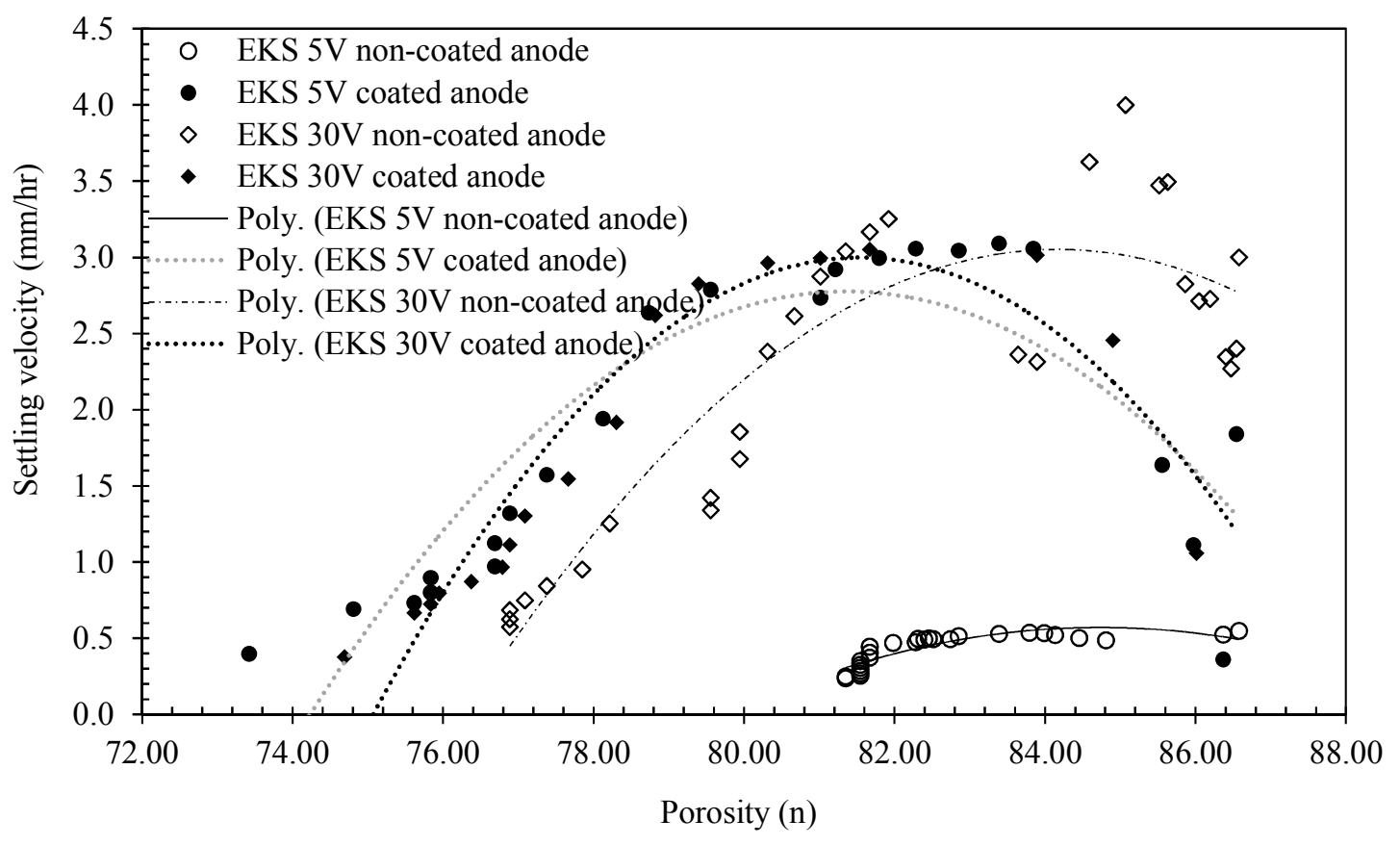

Figure 5 


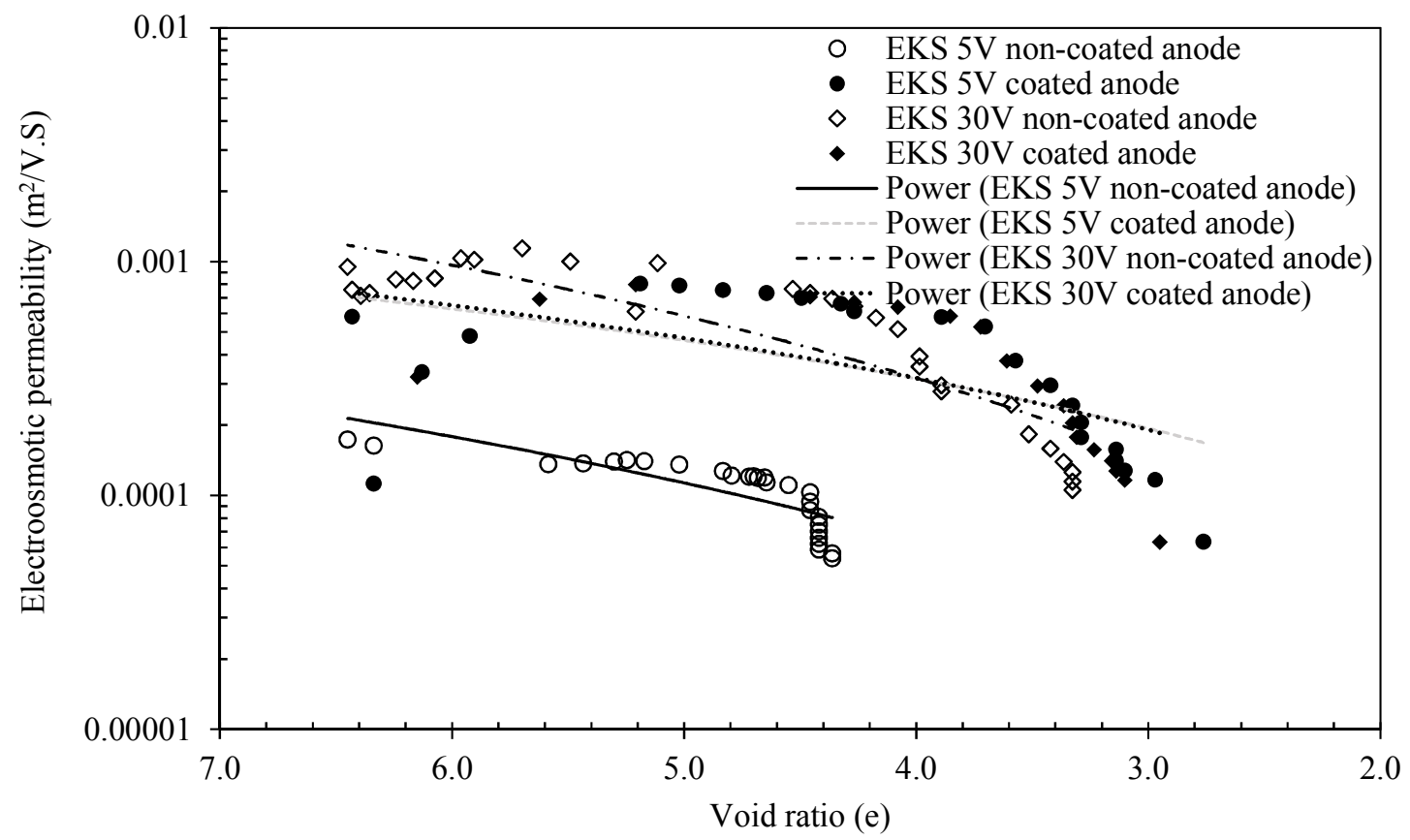

Figure 6 